\title{
Escola católica: Ensino Religioso e BNCC
}

SÉrgio Rogério AZEVEDo JunQueira ${ }^{1}$

SÔNIA ITOZ ${ }^{2}$

Resumo: Está na identidade e na natureza de existir e de ser da escola católica a busca por uma síntese entre cultura e fé. A expressão da identidade da escola católica se coloca como missão de entendimento da razão e da fé presentes na vida, na cultura e na história da humanidade. Ao trabalhar com objetos de conhecimento, a escola católica apresenta valores a assimilar, mas também verdades a descobrir, razão pela qual o ambiente da escola católica deve ser caracterizado pela academicidade, o que exige educadores competentes, convictos, coerentes e comprometidos com a missão de educar evangelizando e evangelizar educando. A escola católica está a serviço do conjunto da sociedade e como instância crítica, com intencionalidade e determinação; deve estar presente, participar e atuar nas situações e nos espaços socioculturais e ser promotora de uma comunidade que seja expressão eclesial. Para isso, deve promover um diálogo sereno e construtivo de colaboração e de respeito mútuo, como reconhecimento recíproco da própria missão, no serviço educativo aos direitos fundamentais da pessoa. Isso quer dizer que, como comunidade educativa, só pode se constituir por causa do encontro e da colaboração de alunos, pais, professores, colaboradores e gestores. Por essa razão, na escola católica, as relações pessoais são de autêntica reciprocidade, de atitudes coerentes e de comportamentos humanizantes. Imbricam-se, assim, conhecimentos com atitudes e posturas para promover um modelo cristão de pessoa. A pesquisa trabalhou com os documentos da Igreja que tratam da escola católica, e o artigo tem por objetivo atingir profissionais da área de Ensino Religioso escolar.

Palavras-chave: Ensino religioso. Escola católica. Identidade. Missão.

\section{Catholic school: Religious Education and BNCC}

Abstract: It is in the identity and nature of existing and being of the Catholic school to seek a synthesis between culture and faith. The expression of the Identity of the Catholic school stands as a mission of understanding reason and faith present in the life, culture and history of humanity. When working with objects of knowledge the Catholic school presents values to be assimilated, but also truths to discover. This reason and why the environment of the Catholic school should be characterized by academicity, which requires competent educators, convinced, coherent and committed to the mission of educating evangelizing and evangelizing educating. The Catholic school is at the service 
of society as a whole and as a critical instance, with intentionality and determination, it must be present, participate and act in the situations, in the sociocultural spaces and be promoter of a community that is ecclesial expression. To this end, it should promote a serene and constructive dialogue of collaboration and mutual respect, as a reciprocal recognition of one's mission in the educational service of the fundamental rights of the person. This means that, as an educational community, it can only consist of meeting and collaborating with the presences of students, parents, teachers, collaborators and managers. For this reason, in the Catholic school, the personal relationships are of authentic reciprocity, of coherent attitudes and of humanizing behaviors. Knowledge and attitude and attitudes are thus imbued in order to promote a Christian model of person. The research worked with Church documents that deal with Catholic school and the article aims to reach professionals in the Area of Religious Schooling.

Keywords: Religious education. Catholic school. Identity. Mission.

\section{Escuela católica: Educación Religiosa y BNCC}

Resumen: Está en la identidad y en la naturaleza de existir y ser de la escuela católica buscar una síntesis entre cultura y fe. La expresión de la Identidad de la escuela católica se plantea como misión de entendimiento de la razón y de la fe presentes en la vida, la cultura y la historia de la humanidad. Al trabajar con objetos de conocimiento la escuela católica presenta valores a asimilar, pero también verdades a descubrir. La razón por la que el ambiente de la escuela católica debe ser caracterizado por la academia, lo que exige educadores competentes, convencidos, coherentes y comprometidos con la misión de educar evangelizando y evangelizando educando. La escuela católica está al servicio del conjunto de la sociedad y como instancia crítica, con intencionalidad y determinación, debe estar presente, participar y actuar en las situaciones, en los espacios socioculturales y ser promotora de una comunidad que sea expresión eclesial. Para ello, debe promover un diálogo sereno y constructivo de colaboración y de respeto mutuo, como reconocimiento recíproco de la propia misión, en el servicio educativo a los derechos fundamentales de la persona. Lo que quiere decir que, como comunidad educativa, sólo puede constituirse por el encuentro y la colaboración de las presencias de alumnos, padres, profesores, colaboradores y gestores. Por esta razón, en la escuela católica, las relaciones personales son de auténtica reciprocidad, de actitudes coherentes y de comportamientos humanizantes. Se relacionan, así, conocimientos con actitudes y posturas, para promover un modelo cristiano de persona. Palabras clave: Educación religiosa. Escuela católica. La identidad. Misión.

\section{Escola católica: um espaço que possibilita a convivência e o conhe- cimento da diversidade}

Coloca-se em pauta, a partir da concepção de escola católica, a orientação dada no documento Base Nacional Comum Curricular (BNCC) para a educação básica no Brasil. O objetivo do artigo é iniciar uma reflexão provocativa entre educadores e articuladores da área de conhecimento e do componente curricular Ensino Religioso. 
Para a constituição de uma escola que exercite a democracia e seja expressão de acolhimento e inclusão de todos e de qualquer um, independentemente de procedência, credo e convicções, é necessário ter presente em seu currículo a pluralidade cultural das sociedades, o que significa se abrir à diversidade religiosa. Isso quer dizer que o universo da educação básica se torna espaço e concede a necessária condição para abrir-se a um conhecimento que também seja convivência com as diferentes expressões culturais e religiosas. Dessa forma, é possível olhar, estudar e estimular afirmações da identidade cultural dos diferentes grupos existentes no Brasil, bem como buscar construir um convívio respeitoso com a multicultura presente no ambiente escolar.

O sistema da educação básica exerce, assim, um papel importante no desvelamento e na desmistificação de pré-conceitos, pois é a falta de formação e de informação que facilita a manipulação de percepções e consciências e que gera discriminação, preconceitos e perseguição a grupos minoritários ou de posturas e expressões diferenciadas do status quo. Os "objetos de conhecimento", antigos "conteúdos", propostos pela BNCC sugerem o trabalho, primeiro, com uma abordagem in loco para conhecer; depois, com análise acadêmico-científica da realidade; e, por fim, com os princípios de direitos humanos, como prevê o Plano Nacional de Educação em Direitos Humanos (BRASIL, 2007). Dessa forma, os estudantes poderão desenvolver competências e habilidades para melhor compreender a realidade e, como consequência, contribuir para a construção de um mundo com mais dignidade para todos, ou seja, mais igualitário nos direitos e nos deveres.

A área de conhecimento Ensino Religioso coloca-se na BNCC com o objetivo de ensino e aprendizagem para garantir o respeito à diversidade cultural, étnica, religiosa e política do país. Entende-se que a multiplicidade de valores humanos e humanitários se dá em um processo de construção de um indivíduo cidadão, com igualdade de direitos e de deveres perante a sociedade em que vive.

Entende-se que, na construção de habilidades, o componente curricular Ensino Religioso leva a:

- conhecer elementos básicos que compõem as manifestações religiosas, a partir das experiências vivenciadas no contexto pelos estudantes;

- analisar a função social das tradições religiosas na organização, na estruturação e na manutenção das diferentes culturas e suas manifestações socioculturais;

- estudar a expressão de atitudes morais como consequência do fenômeno religioso e as representações da consciência como resposta pessoal e das coletividades do ser humano;

- esclarecer o direito à diferença na constituição das organizações religiosas, nas suas estruturas, que têm na liberdade o seu valor inalienável, assim como o debate sobre o sentido da vida para as diversas expressões culturais. 
Em uma leitura "religiosa", a concepção de ser humano é identificada nas elaborações das organizações religiosas, o que passa pela orientação que é dada para o modo como se portar e viver neste mundo. Por isso, os princípios, as doutrinas e os valores religiosos estruturam respostas mediante as concepções; estruturam posturas de vida por meio da organização; estruturam processos para prosseguir a história da humanidade. Entendida a área de conhecimento e os objetos de estudo (BNCC), o componente curricular Ensino Religioso coloca em pauta, especificamente, as relações humanas e os valores que destas demandam.

O cenário do estudo da leitura religiosa interfere, de modo específico, no patrimônio cultural, nas tradições e nas organizações religiosas como concretude de religiosidades e transcendências. Coloca-se aqui o desenvolvimento de competências e habilidades para compreender conteúdos que constituem a história, dada na expressão concreta das mais diferentes realidades e da herança arquitetural expressa nos espaços e nas culturas religiosas. Esses são objetos de aprendizagem que demonstram uma proposta e um modo de educar. E, além disso, diante da diversidade, desencadeiam-se posturas de respeito, tolerância, diálogo e reverência ao diferente. Mas, principalmente, ao fazer com que a liberdade de crença seja respeitada, torna-se objeto primordial de abrir-se ao outro pelo conhecimento, o que amplia o repertório de vocabulário e de percepção do mundo.

Para que isso se dê, é necessário um cuidado primordial com a formação qualificada dos profissionais de Ensino Religioso. Nesse contexto, a formação que dá mais conta de preparar o educador é a ciência da religião, já que trata de uma leitura que busca entender a religiosidade no ser humano e, a partir daí, as manifestações, as organizações, os espaços sagrados, as expressões, os rituais, as simbologias, entre outras.

\section{Escola católica: uma identidade que leva a educar}

Desde a colonização do Brasil por europeus cristãos, a trajetória da Igreja Católica foi a de atuar com forte presença no campo da educação. Desde os primeiros tempos, a Igreja e as escolas católicas passaram por diversas tensões e mesmo conflitos sociais. Nesse processo histórico, no entanto, são as instituições sociais, a Igreja e as escolas católicas que buscam atuar de modo dialógico, acolhedor e com respeito às diferentes organizações civis e religiosas.

A educação feita na escola católica no Brasil está amparada e é respaldada pelo artigo 20 da Lei de Diretrizes e Bases de 1996, que afirma que "as escolas confessionais são constituídas por grupos de pessoas físicas ou por uma ou mais pessoas jurídicas que atendem à orientação confessional e ideologia específicas" (MOURA, 2000, p. 179). Diferentemente de outras áreas do conhecimento para o Ensino Religioso, ainda não existe uma normatização, o que torna um espaço de total liberdade para constituir-se, mas também de enorme risco para a atuação 
didático-pedagógica. Atualmente, a BNCC normatizou concepção de área do conhecimento, e nesta, suas competências, seus objetos de conhecimento, seus conteúdos e suas habilidades para o componente Ensino Religioso, o que faz ser um referencial para o ensino e a aprendizagem.

Em uma perspectiva eclesial católica, evolui, de certa forma, o tratamento dado à educação no Concílio Vaticano II e nas Conferências Episcopais Latino-Americanas. Neste início do século XXI, as escolas católicas organizam-se, em geral como as demais, em comunidade educativa de professores, funcionários, famílias e estudantes de tradições religiosas diversas. Mas, como fenômeno da modernidade, o vínculo, a frequência e a participação efetiva em uma Igreja, católica ou não, são enormemente relativos. Famílias, alunos e educadores em geral, quando questionados sobre o motivo da permanência na escola católica, respondem que são instituições organizadas, têm por tradição qualidade de ensino e são orientadas por valores humanos (ANJOS; ITOZ; JUNQUEIRA, 2015).

Portanto, é por intermédio da expressão "sociocultural" que a escola católica mostra sua identidade própria, ao executar sua missão de ser um meio de evangelização da Igreja, quando participar e tornar efetivo o anúncio da Boa Notícia do Reino. Ao colocar em prática sua missão de educar e evangelizar as culturas, a escola católica tem bastante claro que atua no e com o ser humano, e nas relações entre si e com Deus, para que tenham atitudes e posturas cidadãs à luz dos ensinamentos cristãos.

Nestes últimos tempos, o Ensino Religioso é tratado legalmente como uma área do conhecimento, o que faz com que a escola católica, para continuar a messe que lhe é própria, constitua no seu projeto identitário a pastoral escolar. O Ensino Religioso é campo de conhecimento acadêmico, enquanto a pastoral escolar é o espaço, o tempo e a ação da escola católica que expressa sua identidade e executa sua missão evangelizadora. Em outras palavras, todas as áreas, com seus objetos de conhecimento, suas competências e suas habilidades, tornam-se expressão da identidade, de um carisma fundacional e da missão da escola católica no cuidado que a pastoral escolar precisa implementar e desenvolver.

\section{Ensino Religioso: um ensino que educa a pessoa e uma aprendiza- gem que constrói o cristão}

Hoje a escola é essencialmente um espaço de integração social, o que a torna, cada vez mais, um território carregado de ideologias e instaura condições para que se manifestem diferentes interesses das mais variadas procedências. Nesse contexto, a área de conhecimento Ensino Religioso e suas competências e habilidades a serem desenvolvidas podem ou não colaborar para um tipo de formação do ser humano que seja integral. Por essa razão, o componente curricular Ensino Religioso assume o papel contundente de apresentar diferenciados 
objetos de conhecimento para refletir sobre critérios que fundamentem compromissos éticos e posturas morais, bem como discuti-los e analisá-los, para garantir a expressão das liberdades, o exercício da justiça, o direito a ser diferente, a solidariedade às causas humanas, em busca da plena defesa da dignidade do ser humano.

A compreensão da dimensão religiosa, constitutiva do ser humano, caracteriza-se como objeto de conhecimento a ser trabalhado, tendo presente o contexto com situações específicas e particulares. Assim, a função social do conhecimento escolar identifica e (re)formula questionamentos, elaborações e convicções na ordem do religioso e, gradualmente, constitui a autonomia na alteridade.

Logo, o componente curricular Ensino Religioso deve dar condições e abrir espaços para (re)visitar conteúdos, posturas e argumentos das demais áreas do conhecimento. A abordagem dos objetos de conhecimento, nas suas diferentes temáticas, na ótica do conhecimento religioso, abre horizontes, faz perceber outras elaborações, suscita reflexões, provoca questionamentos, fazendo com que o ensino e a aprendizagem sejam significativos e deem sentido à existência do componente na matriz curricular.

No exercício do diálogo com o diferente, exercita-se o diálogo, o que também faz se abrir para ouvir outras perspectivas, faz ainda conhecer o outro no seu espaço e situação. Assim, para compreender a alteridade, é preciso desenvolver uma competência que escancare o respeito aos diferentes costumes e práticas.

A partir da realidade e do contexto histórico e social, bem como considerando as competências e habilidades a serem desenvolvidas, os objetos de estudo devem despertar os estudantes para:

- a religiosidade presente em si mesmo;

- o fenômeno religioso que se manifesta na sociedade;

- a superação dos pré-conceitos e da discriminação religiosa;

- o respeito à identidade na alteridade;

- a abertura às diferentes expressões religiosas;

- a acolhida solidária e fraterna a todas as pessoas;

- o engajamento social e a implantação da justiça e da promoção do bem comum;

- a corresponsabilidade ecoplanetária.

Portanto, Ensino Religioso é distinto da Catequese, a qual deve ser ministrada para uma comunidade que vive a fé, em um espaço extraclasse e por um período de maior aprofundamento da doutrina cristã-católica. Já o Ensino Religioso acontece na escola, para uma classe de alunos e com conteúdos, objetos do conhecimento, acadêmicos. 
É normativo hoje para a educação básica no Brasil, pela BNCC, que o componente curricular Ensino Religioso deve estar "integrado nos programas escolares e ser ministrado na escola de modo explícito e sistemático, a fim de que não venha a criar-se na mente dos alunos um desequilibrio entre a cultura geral e a cultura religiosa” (CONGREGAÇÃO PARA A EDUCAÇÃO CATÓLICA, 1977, n. 50). Portanto, "o ensino religioso na escola é um direito e um dever dos alunos e dos pais. É uma dimensão fundamental e necessária de toda a educação, bem como uma experiência da liberdade religiosa de cada pessoa" (CNBB, 1983, n. 124).

Portanto, os objetos de conhecimento do Ensino Religioso apresentam um caráter sociocultural, conforme a BNCC, e estão orientados para o conhecimento do fenômeno religioso, com o objetivo de levar à compreensão dos principais entraves existenciais presentes na constituição da diversidade religiosa da sociedade, razão pela qual os objetos de conhecimento devem trabalhar com uma visão de vida presente nas culturas, ter uma linguagem própria, porém sempre aberta ao diálogo, à interdisciplinaridade e à interculturalidade (BRASIL, 2017).

Esses são pressupostos que apontam que o Ensino Religioso deve ser organizado no currículo escolar de forma orgânica e sistemática, para permitir a apropriação de uma linguagem simbólica própria que leve a favorecer uma compreensão do fenômeno sociorreligioso. E, como fim último na educação básica, deve contribuir para que os indivíduos entendam as situações de vida, estejam abertos à convivência com a diversidade, por meio da elaboração de propostas de diálogo e construção coletiva do conhecimento. Como competência final da educação básica, o Ensino Religioso deve levar ao desenvolvimento cognitivo dos estudantes, mediante operações mentais, como perceber, contemplar, narrar, descrever, classificar, comparar, analisar e elaborar, de forma que articule a formação do cidadão e do cristão.

\section{Ensino Religioso: é preciso humanizar a pessoa para humanizar a sociedade}

A área de conhecimento Ensino Religioso, com seus objetos de conhecimento, deve levar a uma leitura do mundo nas várias linguagens, nos diversos fatos, espaços territoriais sagrados e históricos, na arte e com as tecnologias. Os objetos de conhecimento, os conteúdos, devem favorecer os valores sociais, a solidariedade, a superação do preconceito e o acolhimento ao diferente. Para isso, são referenciais fundamentais para o cristianismo:

- a promoção, a defesa e a garantia dos direitos humanos;

- a cultura de paz;

- o desenvolvimento das linguagens;

- o exercício da cidadania;

- o diálogo inter-religioso;

- a participação e o engajamento nos movimentos sociais; 
- as artes e suas produções artísticas;

- a inserção e o engajamento no mundo do trabalho.

É com base neles que, academicamente, o conceito deverá ser construído no ensino e na aprendizagem do Ensino Religioso. Esses são tópicos dos objetos de conhecimento que compõem especificamente a diversidade cultural e religiosa brasileira. Logo, um Ensino Religioso que se pauta pelo conhecimento acadêmico promove a construção do profundo respeito às características da diversidade étnica, racial, religiosa, dentre outras. Só dessa maneira será possível entender que a área de conhecimento Ensino Religioso pode contribuir para a formação integral dos estudantes e favorecer a compreensão dos ambientes, do sistema político, das tecnologias, das artes e dos princípios morais e éticos.

O Ensino Religioso como componente curricular acadêmico, no seu ensino e na sua aprendizagem, trabalha com a organização social, o tempo, o espaço e a seleção criteriosa de materiais e de recursos. Por isso, é dotado de uma linguagem complementar, ou seja, verbal, gestual e simbólica. Trabalha ainda com o fenômeno ontogenético (ser humano individual) e também com o filogenético (ser humano membro da coletividade/social). Por último, trabalha com a aquisição da função simbólica, ou seja, a semiótica ou a representação das linguagens, que é o que dá origem ao pensamento.

Assim, o componente curricular Ensino Religioso entende que, pela capacidade de representar mentalmente os dados da realidade apreendidos pela percepção, o indivíduo se utiliza do significante, que é a imagem mental, a palavra, o gesto ou o símbolo, para representar o significado. É a partir da capacidade de representar que o aluno constrói todo o complexo sistema de significações que darão sentido ao seu existir. Logo, a competência linguística comunicativa de falar, ouvir, ler e escrever é utilizada na preparação, na orientação e na avaliação de todo o processo de ensino e aprendizagem escolar.

É importante ressaltar que a compreensão dos objetos de conhecimento deve respeitar uma comunicação que seja aberta ou que não se restrinja à linguagem de uma tradição religiosa, mas a uma linguagem da ciência da religião, pautada pela linguagem do ser humano no contexto histórico-cultural. A linguagem da ciência da religião é a linguagem religiosa acadêmica e de ensino e aprendizagem na formação da pessoa e do cidadão, por isso é sempre simbólico-evocativa, celebrativa, comunitária e narrativa.

Assim, o Ensino Religioso, na pauta da ciência da religião, deve focalizar os aportes humanos da questão religiosa e utilizar a linguagem do exercício de uma cidadania comprometida com a defesa dos direitos humanos. No processo de ação-reflexão-ação, trabalha com uma avaliação didático-pedagógica que seja elemento integrador entre a aprendizagem dos estudantes e a atuação do professor na construção do conhecimento. 


\section{Ensino Religioso: o que o fundamenta e quais são seus referenciais}

O objeto de estudo do Ensino Religioso:

[...] busca construir, por meio das manifestações religiosas e das filosofias de vida, atitudes de reconhecimento e respeito às alteridades. Trata-se de um espaço de aprendizagens, experiências pedagógicas, intercâmbios e diálogos permanentes, que visam ao acolhimento das identidades culturais, religiosas ou não, na perspectiva da interculturalidade, direitos humanos e cultura da paz (BRASIL, 2017, p. 437).

A definição e a conceituação do objeto de estudo do Ensino Religioso orientam para o conhecimento sobre a vida nas dimensões pessoais, sociais, culturais, ecológicas e transcendentes, ou seja, o componente articula educação e religião, cujos elementos instauram um dinamismo diversificado de tendências, influências e análises, podendo, no entanto, ser ao mesmo tempo complementares. Assim, o norteador da dinâmica social da religião, no espaço da escola, e o estudo das manifestações religiosas como fator de percepção da história da humanidade, explicitada no conceito especificamente de religião, constituem o referencial de ensino e aprendizagem.

O conceito tomado de religião neste trabalho vem da Roma Antiga. Cícero (106-43 a.C.) foi quem sistematizou o conceito de religião, constituído do substantivo "religio", como usado pelos latinos, no sentido de reler, rever os preceitos referentes ao culto aos deuses. Ainda, aproximadamente entre 250-317, Lactâncio deu a interpretação que compreendia a religião como "re+ligare", que significa "ligar de novo o homem a Deus", já que estavam separados pelo pecado original. E, em 354-430, Santo Agostinho, mais no final de sua vida, utilizou o termo "re+eligere" no sentido de "re-escolher a Deus", a quem o homem havia desobedecido com o seu pecado.

Para os romanos, o termo "religio" designava a realização da observância do culto, do respeito e da piedade aos poderes superiores. O entendimento de religião se dava a partir de uma contextualização temporal e histórica do ser humano que se definia perante o mundo e seus semelhantes. Ainda hoje, a religião é expressão que constitui um sentido para a vida de seus seguidores e oferece uma leitura e uma interpretação da vida e do mundo que lhes são significativas.

No Brasil, os especialistas fazem uso da concepção dada por Cícero, que entende religio como um conjunto de crenças e práticas doutrinais, próprias de uma sociedade humana particular organizada, que honra seus deuses e que devota respeito aos demais. Religio pode ainda significar realidades religiosas muito diferentes, no entanto Cícero o qualifica e define como um sistema organizado e público de crenças e práticas enraizadas na cultura particular de um povo. 
A partir do quadro de compreensão anterior, estabeleceram-se princípios estruturais para o componente curricular Ensino Religioso, o que o faz também parte integrante da formação básica em vista da construção da cidadania no educando e no grupo a que pertence. Assim, no currículo escolar, o Ensino Religioso alicerça-se nos princípios acadêmicos de ensino e aprendizagem, que levam ao exercício do engajamento social e do compromisso de entendimento da alteridade, fazendo parte da formação integral dos estudantes. Mesmo em situações de negação do ser religioso, no sentido antropológico, existem dados históricos, organizações sociorreligiosas, espaços sagrados, rituais públicos, simbologias diversas, entre outros, segundo os quais o aluno da educação básica precisa ser preparado para saber, respeitando as religiosidades.

O estudo da religiosidade no ser humano e da religião na realidade sociocultural é decorrência de percepções, pesquisas e estudos, com destaques e sistematizações ocorridos ao longo do século XX. Na Igreja Católica, encontra-se, no discurso do Papa João Paulo II dirigido aos sacerdotes de Roma, referência ao estudo da religião no espaço acadêmico (JOÃO PAULO II, 1980). A CNBB (1983, n. 125) afirma que o "Ensino Religioso se caracteriza pela sua referência aos objetivos e critérios próprios da estrutura escolar e que esse componente curricular é distinto da Catequese, que é dada numa comunidade paroquial". Atualmente, a distinção entre Ensino Religioso como componente curricular e como uma área do conhecimento é assumida na literatura da Igreja, da academia, da educação básica e também compreendida pela sociedade civil.

Nesse aspecto, "a Catequese é entendida como a educação ordenada e progressiva da fé, realizada numa comunidade eclesial, promovendo um conhecimento mais profundo do mistério de Deus" (CNBB, 1983, n. 72). Isso significa dizer também da pessoa e da mensagem salvadora de Jesus Cristo, o que visa a uma adesão da fé, ou seja, fazer com que as pessoas sejam discípulas e seguidoras de Jesus. A Catequese fundamenta o seu conteúdo na teologia e se coloca na perspectiva do conhecimento das grandes experiências religiosas da humanidade. A Catequese busca intencionalmente explorar e trazer presente o sentido da fé e da vida, enquanto o Ensino Religioso busca favorecer aos estudantes a possibilidade de se autoconhecerem, conhecerem os outros e se posicionarem diante do contexto em que vivem e da sua inter-relação com o mundo.

Uma forte e profunda distinção entre Ensino Religioso e Catequese está na característica da linguagem. Cada uma tem uma linguagem própria e adequada aos seus objetivos de ensino e aprendizagem. O Ensino Religioso fundamenta-se na área da ciência da religião, a qual é a área de conhecimento que favorece a construção de argumentos, fundamentações e elaborações que contribuem com uma leitura de mundo. Como conhecimento sociocultural, é possível constatar e comprovar que, no âmbito e no substrato de cada cultura, o elemento religioso sempre está presente e se constitui de diferentes formas, o que justifica o conhecimento religioso como conhecimento da história humana nos seus aspectos socioculturais. 
O Ensino Religioso, componente constituinte da matriz curricular, dá-se nos horários normais da escola, sem prejuízo de tempo, espaço, condições e competências em geral. Ele é o componente que tem por definição principal assegurar o respeito à diversidade cultural e religiosa das sociedades, refutando quaisquer formas de discriminação, preconceito e proselitismo (BRASIL, 1996). Seu objetivo primordial é fazer conhecer as tradições religiosas que os estudantes já trazem de suas famílias e respeitar e salvaguardar a liberdade de expressão religiosa do outro. Busca-se educar para a tolerância, a harmonia, a convivência e a compreensão do outro, pelo entendimento mútuo, pela fraternidade e pela paz, no diálogo e com respeito às diversas tradições religiosas.

O tratamento pedagógico dado aos componentes curriculares é o mesmo em nível de exigência e respeito ofertado ao componente de Ensino Religioso. Os objetos de conhecimento do Ensino Religioso devem subsidiar o entendimento do conhecimento religioso a partir da relação entre as culturas e as tradições religiosas, de modo a proporcionar o conhecimento dos elementos básicos que compõem a manifestação desse fenômeno no ser humano. O desenvolvimento de competências e habilidades em uma sequência racional e lógica deve respeitar o processo de desenvolvimento cognitivo dos estudantes, em cada ano escolar, e, com isso, conhecer e valorizar a trajetória particular de cada cultura, proporcionando o embasamento científico de sua própria tradição religiosa. A metodologia que precisa ser ativa deve, assim, refletir o modo como o fenômeno religioso se apresenta e como foi sendo elaborado historicamente (JUNQUEIRA, 2002).

Logo, objetos do conhecimento e metodologias ativas não apenas identificam o fenômeno religioso, mas desenvolvem uma gradual descoberta de conhecimentos e releitura de mundo, tanto no cotidiano escolar quanto no social. Em decorrência disso, o conhecimento promovido pelo Ensino Religioso supera e ultrapassa o aspecto apenas das informações, mas amplia as visões, as concepções e os fundamentos. Assim, o Ensino Religioso assume, com os outros componentes escolares, o papel de provocar na comunidade educativa questionamentos e reelaborações do processo de humanização no contexto de múltiplas relações sociais e planetárias.

Com isso, o Ensino Religioso é um componente que precisa ir além do supérfluo, da materialidade das coisas, dos acontecimentos corriqueiros, dos gestos sem sentido, dos ritos sem significado e das normas. Deve trabalhar com um conhecimento acadêmico elaborado e sistematizado, enfim, que ajude a interpretar a realidade com profundidade e leve a atuar na sociedade de um modo que seja transformador.

Pode-se dizer que a religião, quando e se entendida como o estudo das diferentes manifestações que interferem na formação da sociedade, orienta o ensino e a aprendizagem do Ensino Religioso no espaço escolar. Afirma-se também que a ciência da religião é o referencial que subsidia a aplicação didática para o cotidiano 
da sala de aula, favorecendo aos estudantes da educação básica uma compreensão maior da cultura das diferentes organizações religiosas, e é a ciência acadêmica que capta, analisa e investiga sistematicamente as religiões em suas manifestações e organizações socioculturais, a partir de fatos ou fenômenos percebidos como religiosos.

Como qualquer fenômeno academicamente, não se questiona a validade ou a qualidade de uma religião. Primeiro, percebe-se; depois, constitui-se em objeto de estudo; então, analiticamente, é considerada ou não pertinente para tratar como ensino e aprendizagem. A partir disso, metodologicamente percebe-se até então que as religiões são sistemas de sentido, dado pelo ser humano, formalmente idênticos, mesmo que expressem uma enorme diversidade sociocultural nas suas concepções, manifestações e organizações. Portanto, é a ciência da religião que constitui os fundamentos e os referenciais que estabelecem a base do conhecimento para o trabalho de ensino e aprendizagem do Ensino Religioso.

\section{Uma concepção de ensino e aprendizagem para o Ensino Religioso}

O Ensino Religioso, assim como os demais componentes do currículo escolar, trabalha, consciente e intencionalmente, com o dado sociocultural e o desenvolvimento cognitivo dos alunos e a partir deles. Trata-se de:

[...] um espaço de aprendizagens, experiências pedagógicas, intercâmbios e diálogos permanentes, que visam o acolhimento das identidades culturais, religiosas ou não, na perspectiva da interculturalidade, direitos humanos e cultura da paz. [...] Considerando esses pressupostos, e em articulação com as competências gerais da BNCC, a área de Ensino Religioso - e, por consequência, o componente curricular de Ensino Religioso -, devem garantir aos alunos o desenvolvimento de competências específicas (BRASIL, 2017, p. 437).

A BNCC propõe unidades temáticas, das quais estabelece objetos de conhecimento e habilidades que devem pautar os planejamentos e, destes, a ação pedagógica do ensino e da aprendizagem. Porém, antes disso, é importante o professor se apropriar, com muita competência acadêmica, do que é pedido sobre as competências a serem desenvolvidas no aluno da educação básica. Diz a BNCC (BRASIL, 2017, p. 437) que o Ensino Religioso deve garantir aos alunos o desenvolvimento de competências para:

1. Conhecer os aspectos estruturantes das diferentes tradições/ movimentos religiosos e filosofias de vida, a partir de pressupostos científicos, filosóficos, estéticos e éticos. 2. Compreender, valorizar e respeitar as manifestações religiosas e filosofias de vida, suas experiências e saberes, em diferentes tempos, espaços e territórios. 3. Reconhecer e cuidar de si, do outro, da coletividade e da natureza, 
enquanto expressão de valor da vida. 4. Conviver com a diversidade de crenças, pensamentos, convicções, modos de ser e viver. 5. Analisar as relações entre as tradições religiosas e os campos da cultura, da política, da economia, da saúde, da ciência, da tecnologia e do meio ambiente. 6. Debater, problematizar e posicionar-se frente aos discursos e práticas de intolerância, discriminação e violência de cunho religioso, de modo a assegurar os direitos humanos no constante exercício da cidadania e da cultura de paz.

A partir da compreensão do trabalho com desenvolvimento de competências, o professor organiza situações-problema com pesquisas, vivências, relatos, estudo de meio em tempos e espaços das religiões. Para isso, o professor precisa ainda desenvolver metodologias ativas ou que façam os alunos buscarem o entendimento das religiões por diversas formas de conhecer e aprender.

O tratamento metodológico do Ensino Religioso se delineia a partir da caracterização da matriz teórica e do fazer pedagógico, propondo competências e habilidades a serem desenvolvidas; objetivos a serem atingidos e que pautam o ensino e a aprendizagem; objetos de conhecimento (conteúdos); projetos; metodologias; avaliação; e reproposta do projeto anual e dos planejamentos de cada etapa (bimestre, trimestre e semestre).

O processo de ensino e aprendizagem é articulado considerando sempre o de-senvolvimento afetivo, cognitivo, psicossocial, físico, estético, ético, moral e religioso, pois o ser humano é um ser em constante desenvolvimento, e sua relação com os diferentes tipos de conhecimento tem inferência nos estágios da maturação humana.

A linguagem do Ensino Religioso é a linguagem do conhecimento, por isso é pedagógica, e nunca religiosa, o que quer dizer que se sustenta em habilidades que levem à competência de construir atitudes, posturas e valores. Assim, o aluno é levado a:

- analisar e acolher as experiências religiosas previamente construídas, as quais favorecem a capacidade de vivenciar uma relação de abertura às diferentes culturas;

- elaborar e vivenciar comportamentos éticos, autônomos, responsáveis e de respeito ao bem comum, para estimulá-los e fortalecê-los;

- exercitar-se em discussões, debates, criatividade e respeito à ordem democrática, que preservem os direitos e os deveres dos cidadãos;

- testemunhar o respeito ao diferente e criar condições e possibilidades para que cada um desenvolva a sua identidade pessoal.

É evidente que, para isso, será necessário estabelecer critérios didáticos que se colocam a partir da forma de organizar e trabalhar os objetos de conhecimento, possibilitando a construção do ensino e da aprendizagem.

Dessa forma, o tratamento didático-pedagógico no Ensino Religioso precisa considerar: 
- os conhecimentos prévios dos estudantes, as demandas locais, os interesses, as sensibilidades e as possibilidades;

- o respeito às diferentes tradições religiosas, de modo que os estudantes valorizem, assumam, aprofundem e vivenciem a própria cultura e tradição religiosa;

- metodologias ativas, que permitam ser criativo no processo de aprender e socializar conhecimentos;

- a participação, a interação, a cooperação, a escuta do outro, o respeito ao diferente, a abertura para novas aprendizagens e o desenvolvimento da autonomia;

- a adequação de recursos, de linguagem, de textos, de alegorias etc., permitindo que os estudantes construam significados, reflitam sobre as diferentes tradições religiosas e se sensibilizem diante do transcendente ou do mistério;

- as necessidades dos estudantes de estabelecer relações, interações e conexões entre os conhecimentos do próprio universo religioso e os de outro.

O Ensino Religioso será organizado por competências e habilidades a serem desenvolvidas e por objetos de conhecimento que apontem para a necessidade de uma interação entre quem aprende e quem ensina e que demonstrem conhecimento histórico-cultural significativo. Será desenvolvido por meio de uma linguagem que se propõe a auxiliar e a desenvolver a sensibilidade, o diálogo, a tolerância e a convivência pacífica, respeitando a pluralidade cultural e religiosa brasileira e que, no processo, possa responder às questões existenciais: quem sou eu? De onde vim? Para onde vou? Qual é o sentido da minha existência?

Os objetos de conhecimento devem contemplar uma cosmovisão que favoreça a compreensão da estrutura e dos conceitos das religiões, visando sempre estabelecer as formas de expressão que explicitam, por meio dos costumes, das tradições e da linguagem, aquilo que influencia as relações sociais (BRASIL, 2017).

\section{Concluindo: um Ensino Religioso que se faz fazendo}

Compreende-se que o Ensino Religioso é uma das áreas de conhecimento da educação básica e que compõe todo o processo da educação integral do aluno. É também operacionalizado por meio de um modelo de currículo articulado com a teoria educacional e a prática pedagógica, ou seja, passa por um bom e bem elaborado planejamento para dar conta da ação pedagógica. É isso que permite ao estudante o domínio de diferentes linguagens, a compreensão de diversos fenômenos, sejam físicos, sejam sociais, e construir argumentações que levam a elaborar propostas e a enfrentar as diversas situações de sua vida (TEIXEIRA, 2006). 
O Ensino Religioso aproxima estudantes e professores, estimulando a prática de ensino e aprendizagem pela pesquisa de campo, das organizações, dos ritos, dos símbolos, dentre outros, mas que deve ser feito de forma científico-acadêmica. Seu objeto de estudo é o conhecimento religioso, construído empírica e sistematicamente a partir das tradições religiosas, observando as unidades temáticas (BRASIL, 2017) de estudo sobre religiões e os objetos de conhecimento, conforme o desenvolvimento cognitivo e o desenvolvimento da fé do educando (FOWLER, 1992).

Entende-se que a compreensão do fenômeno religioso na sociedade utiliza-se de uma metodologia ativa que possibilita:

- o contato para a observação do fenômeno religioso em suas múltiplas expressões;

- a pesquisa para obter a informação de dados como aproximação de aspectos do conhecimento religioso;

- a análise para a reflexão do confronto didático-pedagógico entre conhecimento teórico e prático;

- a avaliação como exercitação de competências e habilidades que levam à elaboração de concepções.

Assim, a área de conhecimento Ensino Religioso busca desenvolver a compreensão da diversidade religiosa na realidade brasileira e de mundo. Porém, o principal é que possa desenvolver habilidades de respeito e acolhida às diferentes expressões religiosas, para que desenvolvam competências que favoreçam o diálogo inter-religioso, multicultural e ecumênico.

Recebido em: 16/10/2018

Revisado pelo autor em: 03/12/2018 Aceito para publicação em: 15/12/2018

\section{Notas}

1 Professor livre-docente (2012) e pós-doutor (2010) em Ciência da Religião pela Pontifícia Universidade Católica de São Paulo. Pós-doutorado em Geografia da Religião pela Universidade Federal do Paraná (Bolsista CAPES - 2018). Professor titular da Pontifícia Universidade Católica do Paraná (2008). Doutor (2000) e Mestre (1996) em Ciências da Educação pela Univeristá Pontifícia Salesiana (Roma - Itália). Licenciatura em Pedagogia pela Universidade de Uberaba (1990). Bacharel em Ciências Religiosas pelo Instituto Superior de Ciências Religiosas (1987). Pesquisador colaborador do LEER da Universidade Estadual de Londrina. É consultor e orientador em Educação e Religião. Líder do Grupo de Pesquisa Educação e Religião (GPER). E-mail: srjunq@gmail.com

2 Mestre em Educação (1993) pela Pontifícia Universidade Católica de São Paulo. Graduação em Filosofia (1990) pela FAI. Graduação em Teologia pela Faculdade de Teologia Nossa Senhora da Assumpção (1990). Membro e pesquisadora do Instituto de Pesquisa e Formação Educação e Religião (IPFER). Assessora, palestrante, escritora e autora de artigos e de livros didáticos de Ensino Religioso e Pastoral Escolar. Coordenadora do Departamento de Estudos Filosóficos, Sociológicos e Ensino Religioso e de Pastoral Escolar do Colégio Emilie de Villeneuve/SP. E-mail: soniadeitoz@gmail.com 


\section{Referências}

ANJOS, Marcio; ITOZ, Sonia; JUNQUEIRA, Sergio. Pastoral escolar: práticas e provocações. Aparecida: Santuário, 2015.

BRASIL. Lei n. 9.394/96, de 20 de dezembro de 1996. Estabelece as diretrizes e bases da educação nacional. Diário Oficial [da] União, Brasilia, DF, 23 dez. 1996. Disponível em: http://www.planalto.gov.br/ccivil_03/leis/19394.htm. Acesso em: 14 out. 2018.

. Comitê Nacional de Educação em Direitos Humanos. Plano Nacional de Educação em Direitos Humanos. Brasilia: Secretaria Especial dos Direitos Humanos, Ministério da Educação, Ministério da Justiça, UNESCO, 2007.

- Secretaria Especial dos Direitos Humanos. Diversidade religiosa e direitos humanos - Cartilha. Brasília: Secretaria Especial dos Direitos Humano, 2017. Disponível em: http://www.dhnet.org.br/dados/cartilhas/a_pdf_ dht/cartilha_sedh_diversidade_religiosa.pdf. Acesso em: 14 out. 2018.

. Ministério da Educação. Base nacional comum curricular. Brasília: MEC, 2017.

CNBB - CONFERENNCIA NACIONAL DOS BISPOS DO BRASIL. Catequese renovada: orientações e conteúdo. Itaici, 1983.

CONGREGAÇÃO PARA A EDUCAÇÃO CATÓLICA. A escola católica. Vaticano, 1977.

FOWLER, James. Estágios da fé: a psicologia do desenvolvimento humano e a busca de sentido. São Leopoldo: Sinodal, 1992.

JOÃO PAULO II. Discurso aos Sacerdotes de Roma. Roma, 5 mar. 1980. Disponível em: http://w2.vatican.va/content/john-paul-ii/pt/speeches/1981/ march/documents/hf_jp-ii_spe_19810305_sacerdoti-diocesi-roma.html. Acesso em: 14 out. 2018.

JUNQUEIRA, Sérgio Rogério Azevedo. Pastoral escolar: conquista de uma identidade. Petrópolis: Vozes, 2002.

MOURA, Laercio. A educação católica no Brasil: passado, presente e futuro. São Paulo: Loyola, 2000.

TEIXEIRA, Faustino. Educação inter-religiosa e educação para alteridade. In: SCARLATELLI, Cleide; STRECK, Danilo; FOLLMANN, José. Religião, cultura e educação. São Leopoldo: Unisinos, 2006. p. 29-40. 